\title{
Her-2/neu amplification and breast cancer survival: Results from the Shanghai breast cancer study
}

\author{
ALICIA BEEGHLY-FADIEL ${ }^{1}$, NOBUHIKO KATAOKA ${ }^{1}$, XIAO-OU SHU ${ }^{1}$, \\ QIUYIN CAI ${ }^{1}$, SANDRA L. DEMING ${ }^{1}$, YU-TANG GAO ${ }^{2}$ and WEI ZHENG ${ }^{1}$ \\ ${ }^{1}$ Vanderbilt Epidemiology Center, Vanderbilt University School of Medicine, Nashville, TN 37232, USA; \\ ${ }^{2}$ Department of Epidemiology, Shanghai Cancer Institute, Shanghai, 200032, P.R. China
}

Received November 16, 2007; Accepted January 28, 2008

\begin{abstract}
Her-2/neu is a member of the epidermal growth factor receptor family that has been found to be overexpressed or amplified in $\sim 20-30 \%$ of breast cancers. Negative prognosticators and a shortened survival have been shown to be associated with these changes in Her-2/neu, but previous studies have consisted of predominantly Caucasian populations. Additionally, chromogenic in situ hybridization (CISH) has been suggested to be a potential alternative to fluorescent in situ hybridization (FISH), the expensive and laborintensive gold standard assay currently used for Her-2/neu amplification. This study evaluated breast cancer samples from 313 Chinese women participating in the Shanghai breast cancer study, of which 100 (32\%) were found to have Her-2/neu amplification by either FISH or CISH methodologies. After a mean follow-up period of 6.67 years, Her-2/neu amplification was found to be significantly associated with an increased hazard of death, regardless of which assay was used to detect amplification. Patients with Her-2/neu amplification were $\sim 60 \%$ more likely to die of the disease (HR: $1.6,95 \%$ CI: 1.0-2.6) than patients without amplification, even after adjusting for age, stage, menopausal status, chemotherapy, radiotherapy and tamoxifen treatment. Furthermore, the negative prognostic effect of Her-2/neu varied by cancer stage, with greater risks of death evident among later stage patients. This study supports a negative prognostic role for Her-2/neu in breast cancer survival among a Chinese population, irrespective of whether FISH or CISH is used to detect amplification of the Her-2/neu gene.
\end{abstract}

\section{Introduction}

The Her-2/neu oncogene (c-erbB-2), a member of the epidermal growth factor receptor family, encodes a $185 \mathrm{kDa}$

Correspondence to: Dr Wei Zheng, Vanderbilt Epidemiology Center, 2525 West End Avenue, 8th floor, Nashville, TN 372031738, USA

E-mail: wei.zheng@vanderbilt.edu

Key words: Her-2/neu, amplification, breast cancer, prognosis transmembrane glycoprotein with tyrosine kinase activity $(1,2)$. Her-2/neu has been mapped to the long arm of $17 q 21.1$ (3) and its protein product functions as a co-receptor in the initial steps of signal transduction after growth factor binding and receptor dimerization (4-7). Functional Her-2/neu is essential for normal growth and development (8-10). However, high levels of expression result in increased cellular proliferation (11) and have been shown to be sufficient for cellular transformation $(12,13)$. While Her-2/neu has no preferred growth factor ligand, it dimerizes with other receptors of the ErbB family and potentiates multiple proliferative and cell survival signaling cascades (4-7). The oncogenic potential of Her-2/neu has been attributed to its capacity for autophosphorylation and constitutive homodimerization $(7,12,14)$, as well as its ability to heterodimerize with other members of the Her family, likely resulting in an increased ligand binding affinity and decreased receptor internalization and degradation $(6,7,15)$.

Overexpression of the protein or amplification of the Her-2/neu gene has been shown to occur in $\sim 20-30 \%$ of breast cancers (16), and to be associated with a variety of negative prognostic factors, including larger tumor size, high nuclear and histological grade, steroid hormone receptor negativity, lymph node involvement, tumor aneuploidy and high proliferation indices (17-24). Patients with Her-2/neu positive tumors have also been found to have higher risks of metastasis, disease recurrence and death $(16,17,25-32)$. All of these studies, however, were conducted in predominantly Caucasian populations. While Her-2/neu is generally considered to be a marker of tumor aggressiveness (22), the percentage of Chinese breast cancer patients with Her-2/neu amplification and the effect of this amplification on breast cancer survival among a Chinese population, is less clear.

With the advent of trastuzumab (Herceptin ${ }^{\circledR}$, Genentech, Inc.), a recombinant humanized monoclonal antibody against the extracellular domain of the Her-2/neu protein, patients can receive targeted cytotoxic treatment against their Her-2/neu positive breast tumors $(33,34)$. This makes the correct assessment of Her-2/neu crucial for appropriate clinical decision making (35). Two assays for Her-2/neu evaluation are currently in clinical use: the Hercep Test ${ }^{\mathrm{TM}}$ (Dako Corp., Carpenteria, CA) uses an immunohistochemical (IHC) approach to detect the Her-2/neu protein overexpression, and the PathVysion ${ }^{\mathrm{TM}}$ test (Vysis Inc., Downers Grove, IL) uses a 
fluorescence in situ hybridization (FISH) method to detect the amplification of the Her-2/neu gene. IHC is simpler, faster and readily available in most pathology laboratories. However, several studies have reported that the assay is overly sensitive and has a high false positive rate (36-40). FISH is considered to be the gold standard for Her-2/neu evaluation, but it is expensive and frequently impractical for use in routine clinical settings (40-46). Chromogenic in situ hybridization (CISH) has been shown to be a viable alternative to FISH whereby the fluorescent signal is replaced with a chromogenic label, allowing for detection by standard microscopy $(45,47-52)$. However, the assessment of Her-2/neu by CISH has yet to be used in a large prognostic study. To address this issue, this study was undertaken to evaluate the association between Her-2/neu amplification, as assessed by FISH or CISH methodologies, and breast cancer survival among Chinese women participating in the Shanghai breast cancer study.

\section{Materials and methods}

Study design and subjects. This cohort of primary breast cancer patients consisted of a subset of cases from The Shanghai Breast Cancer Study, Shanghai, China, 1996-2002, a large population-based study of permanent Chinese residents in urban Shanghai $(53,54)$. Eligible women were those diagnosed with breast cancer between August 1996 and March 1998, without a previous cancer diagnosis and who were still alive at the time of the interview. Through a rapid case ascertainment system, and the population-based Shanghai Tumor Registry, 1,602 eligible breast cancer cases were identified, of which 1,459 (91.1\%) completed in person interviews. Reasons for non-participation included refusal $(\mathrm{N}=109,6.8 \%)$, death before the interview $(\mathrm{N}=17,1.1 \%)$ and the inability to be located $(\mathrm{N}=17,1.1 \%)$. Structured questionnaires were used to obtain detailed information on demographic factors, menstrual and reproductive histories, physical activity, tobacco and alcohol use, weight history and family history of cancer. The information on cancer diagnosis, tumor-node-metastasis (TNM) stage of disease and treatment received was abstracted by medical chart review. Cancer diagnoses were confirmed by two senior pathologists.

The 1,459 breast cancer patients were followed through July 2005 by surveys coupled with record linkage of death certificates from the Vital Statistics Unit of the Shanghai Center for Disease Control and Prevention. The majority of patients were contacted either in person or by telephone $(\mathrm{N}=1,378,94.4 \%)$, of which 266 were found to have died. The survival status of the remaining 77 patients was determined by death registry linkage, and of these, 47 were deceased. The remaining 30 patients were assumed to be alive six months prior to the date of the registry search to allow for the possible delay of death record entry. Four subjects had insufficient information for record linkage and were considered to be lost to follow-up.

Sample collection and processing. Paraffin-embedded formalin-fixed tumor tissues were sectioned and mounted onto charged slides for Her-2/neu analysis. Due to budget constraints, only a subset of the 1,455 breast cancer patients included in the present study were analyzed, 108 by FISH and 205 by CISH.

Fluorescence in situ hybridization. Dual-color FISH was performed using the PathVysion test (Vysis Inc.) according to the manufacturer's instructions. The kit included a SpectrumGreen probe for the centromeric region of chromosome 17 and a SpectrumOrange HER-2/neu locusspecific probe. Briefly, tissue sections were baked onto slides at $60^{\circ} \mathrm{C}$ overnight. Samples were deparaffinized by immersing them twice in Hemo-De (Fisher Scientific, Pittsburgh, PA) for $15 \mathrm{~min}$ at room temperature, dehydrated twice in $100 \%$ $\mathrm{EtOH}$ for $10 \mathrm{~min}$ at room temperature and air-dried. The slides were treated with microwave radiation in $10 \mathrm{mM}$ citric acid ( $\mathrm{pH} \mathrm{6)}$ at $700 \mathrm{~W}$ for 3 min followed by immersion in 2X SSC for $5 \mathrm{~min}$ at room temperature. Then the slides were treated with a pepsin $(4 \mathrm{mg} / \mathrm{ml}$ in $0.9 \% \mathrm{NaCl}, \mathrm{pH} 1.5)$ digestion for $20 \mathrm{~min}$ at $37^{\circ} \mathrm{C}$, rinsed with de-ionized water for $2 \mathrm{~min}$ and baked at $60^{\circ} \mathrm{C}$ for $20 \mathrm{~min}$. Dual-color FISH was performed so that the probes and target DNA were codenatured at $80^{\circ} \mathrm{C}$ for 2 min and incubated on the samples under rubber cement-sealed coverslips at $37^{\circ} \mathrm{C}$ overnight. After hybridization, the slides were washed twice in $1.5 \mathrm{M}$ urea at $45^{\circ} \mathrm{C}$ for $15 \mathrm{~min}$, once in $2 \mathrm{X} \mathrm{SSC} \mathrm{(pH} \mathrm{7.0)} \mathrm{for} 5 \mathrm{~min}$, and once in $2 \mathrm{X} \mathrm{SSC} / 0.1 \% \mathrm{NP}-40$ for $5 \mathrm{~min}$. The tissue samples were then counterstained with DAPI II (Vysis Inc.). The slides were viewed with a Zeiss Axioscope ultravioletequipped microscope and triple bandpass filter unit (Chroma Technology, Brattleboro, VT). For each case, one H\&E companion slide was used for pathological confirmation and establishment of the location of malignant tumor areas. Five non-adjacent cancer areas were randomly selected and 20 non-overlapping interphase nuclei were scored in each area. The nuclei from stromal elements were not enumerated. Green chromosome 17 centromere signals and orange HER-2/neu signals were simultaneously counted in each nucleus. The average copy number per nucleus was calculated for the two signals in all five areas. An amplification ratio was calculated by dividing the mean HER-2/neu copy number by that of the chromosome 17 centromere. A sample with an amplification ratio of $<1.5$ was considered to have no amplification. Samples with ratios between 1.5 and 2.0 were considered to have low; those between 2.1 and 4.0 , moderate, and those with amplification ratios $>4.0$, high amplification. When dichotomized, the samples with no amplification were compared to those with any level of amplification.

Chromogenic in situ hybridization. CISH reagents were from Zymed (Zymed Laboratories, South San Francisco, CA) and were used according to the manufacturer's instructions with minor modifications. Briefly, tissue sections were baked onto slides at $60^{\circ} \mathrm{C}$ overnight. Samples were deparaffinized by immersing them twice in xylene for $15 \mathrm{~min}$ at room temperature, dehydrated twice in $100 \% \mathrm{EtOH}$ for $10 \mathrm{~min}$ at room temperature and then air-dried. Slides were treated with microwave radiation in pre-warmed pretreatment buffer at $700 \mathrm{~W}$ for $3 \mathrm{~min}$. Enzymatic digestion was carried out with pepsin at $37^{\circ} \mathrm{C}$ for 3 min followed by immersion of graded diluted ethanol, 70, 85, 95 and $100 \%$ at $4^{\circ} \mathrm{C}$ for 3 min each and then air-dried at room temperature. After the Her-2/neu 
Table I. Clinicopathologic characteristics of cases from the Shanghai breast cancer study and Her-2/neu amplification status.

\begin{tabular}{|c|c|c|c|c|c|}
\hline & \multirow{2}{*}{$\begin{array}{c}\text { SBCS } \\
\text { Breast cancer cases } \\
(\mathrm{N}=1,455)\end{array}$} & \multirow{2}{*}{$\begin{array}{l}\text { Her- } 2 / \text { neu analyzed } \\
\text { Breast cancer cases } \\
\qquad(\mathrm{N}=313)\end{array}$} & \multicolumn{3}{|c|}{ Her-2/neu status } \\
\hline & & & Not amplified ( $\mathrm{N}=213)$ & Amplified (N=100) & $\mathrm{p}$-value ${ }^{\mathrm{a}}$ \\
\hline & $\mathrm{N}(\%)^{\mathrm{b}}$ & $\mathrm{N}(\%)^{\mathrm{b}}$ & $\mathrm{N}(\%)^{\mathrm{b}}$ & $\mathrm{N}(\%)^{\mathrm{b}}$ & \\
\hline \multicolumn{6}{|l|}{ Age at diagnosis } \\
\hline 45 or younger & $583(40.1)$ & $145(46.3)$ & $98(46.0)$ & $47(47.0)$ & 0.87 \\
\hline Older than 45 & $872(59.9)$ & $168(53.7)$ & $115(54.0)$ & $53(53.0)$ & \\
\hline \multicolumn{6}{|l|}{ Menopausal status } \\
\hline Premenopausal & $950(65.3)$ & $204(65.2)$ & $140(65.7)$ & $64(64.0)$ & 0.76 \\
\hline Post-menopausal & $505(34.7)$ & $109(34.8)$ & $73(34.3)$ & $36(36.0)$ & \\
\hline \multicolumn{6}{|c|}{ TNM stage of disease } \\
\hline $0-\mathrm{I}$ & $358(24.6)$ & $70(22.4)$ & $51(23.9)$ & $19(19.0)$ & 0.82 \\
\hline IIa & $508(34.9)$ & $117(37.4)$ & $81(38.0)$ & $36(36.0)$ & \\
\hline $\mathrm{IIb}$ & $320(22.0)$ & $85(27.2)$ & $56(26.3)$ & $29(29.0)$ & \\
\hline III-IV & 165 (11.3) & $24 \quad(7.7)$ & $16(7.5)$ & $8(08.0)$ & \\
\hline Unknown & $104(07.2)$ & $17(5.4)$ & $9(4.2)$ & $8(08.0)$ & \\
\hline \multicolumn{6}{|l|}{ Chemotherapy } \\
\hline Yes & $1367(94.0)$ & $298(95.2)$ & $204(95.8)$ & $99(94.0)$ & $1.00+$ \\
\hline No & 70 & $12(3.8)$ & 8 (3.8) & $4(4.0)$ & \\
\hline Unknown & $18 \quad(1.2)$ & $3(1.0)$ & $1 \quad(0.5)$ & $2(2.0)$ & \\
\hline \multicolumn{6}{|l|}{ Radiotherapy } \\
\hline Yes & $566(38.9)$ & $127(40.6)$ & $85(39.9)$ & $42(42.0)$ & 0.85 \\
\hline No & $690(47.4)$ & $153(48.9)$ & $104(48.8)$ & $49(49.0)$ & \\
\hline Unknown & $199(13.7)$ & $33(10.5)$ & $24(11.3)$ & $9(9.0)$ & \\
\hline \multicolumn{6}{|l|}{ Tamoxifen treatment } \\
\hline Yes & $921(63.3)$ & $207(66.1)$ & $144(67.6)$ & $63(63.0)$ & 0.09 \\
\hline No & $263(18.1)$ & $50(16.0)$ & $28(13.2)$ & $22(22.0)$ & \\
\hline Unknown & $271(18.6)$ & $56(18.0)$ & $41(19.3)$ & $15(15.0)$ & \\
\hline
\end{tabular}

${ }^{\text {a }}$ p-value from $\chi^{2}$ test or Fisher's exact test where indicated $(+)$; tests of association do not include patients with unknown variable status. ${ }^{b}$ Column percents may not sum to 100 due to rounding error.

probe $(10 \mathrm{ml} / \mathrm{slide})$ was added, the samples were sealed under rubber cemented coverslips, denatured on a hot plate $\left(94^{\circ} \mathrm{C}\right)$ for $3 \mathrm{~min}$ and incubated overnight at $37^{\circ} \mathrm{C}$. The slides were washed $(0.5 \mathrm{X} \mathrm{SSC})$ for $5 \mathrm{~min}$ and the hybridized probe was detected using the $\mathrm{CISH}$ detection reagents of antidigoxigenin-FITC, anti-FITC-peroxidase and diaminobenzidine as the chromogen. The samples were counterstained with hematoxylin, mounted and evaluated by an ordinary transmitting light microscope under a $20 \mathrm{X}$ objective. The criteria for successful CISH analysis included the identification of at least one copy of the Her-2/neu gene per nucleus in most cancer cells and appropriate high temperature target retrieval and enzyme digestion as indicated by well-preserved cell morphology. Samples with 1-4 copies of Her-2/neu were considered to have no amplification, while those with five or more copies were considered to have Her-2/neu amplification.

Statistical analysis. The relationships between clinicopathological features of disease and Her-2/neu amplification status were evaluated with the $\chi^{2}$ test of association or Fisher's exact test when warranted. Survival time was defined as the time from diagnosis to death, or else censored at the date of the last contact. Survival functions were generated by the Kaplan-Meier method and differences between strata were evaluated by the log-rank test. Cox proportional hazards regression was used to model the risk of death associated with Her-2/neu in both unadjusted models and in models including other known or potential prognostic factors, such as age at diagnosis, stage of disease, menopausal status and types of treatment received, such as chemotherapy, radiotherapy and tamoxifen treatment. All tests were conducted with a significance level of $\alpha=0.05$ and all $p$-values were based on two-tailed tests of significance.

\section{Results}

The clinicopathological characteristics of all cases from the Shanghai Breast Cancer Study, as well as the subset of patients included in this analysis, are shown in Table I. The distribution of menopausal status, stage of disease, chemotherapy, radio- 
Table II. Survival analysis of breast cancer patients by Her-2/neu amplification status.

\begin{tabular}{|c|c|c|c|c|c|c|}
\hline Her-2/neu assay $(\mathrm{N})$ & Cases & Deaths & 5 year survival $\%$ & $\operatorname{HR}(95 \% \mathrm{Cl})^{\mathrm{a}}$ & $\begin{array}{l}\text { Overall survival } \\
\mathrm{HR}(95 \% \mathrm{Cl})^{\mathrm{b}}\end{array}$ & $\operatorname{HR}(95 \% \mathrm{Cl})^{\mathrm{c}}$ \\
\hline \multicolumn{7}{|l|}{ FISH (N=108) } \\
\hline Not amplified & 63 & 10 & 85.5 & 1.0 reference & 1.0 reference & 1.0 reference \\
\hline Amplified & 45 & 12 & 78.3 & $1.9(0.8-4.3)$ & $1.9(0.8-4.3)$ & $1.7(0.7-4.2)$ \\
\hline \multicolumn{7}{|l|}{ CISH (N=205) } \\
\hline Not amplified & 150 & 33 & 88.1 & 1.0 reference & 1.0 reference & 1.0 reference \\
\hline Amplified & 55 & 18 & 76.4 & $1.6(0.9-2.8)$ & $1.7(0.9-3.0)$ & $1.7(0.9-3.1)$ \\
\hline \multicolumn{7}{|c|}{ CISH or FISH $(\mathrm{N}=313)$} \\
\hline Not amplified & 213 & 43 & 86.6 & 1.0 reference & 1.0 reference & 1.0 reference \\
\hline Amplified & 100 & 30 & 78.1 & $1.6(1.0-2.6)$ & $1.6(1.0-2.6)$ & $1.6(1.0-2.6)$ \\
\hline
\end{tabular}

${ }^{a}$ Unadjusted, badjusted for age and stage and cadjusted for age, stage, menopausal status, chemotherapy, radiotherapy and tamoxifen treatment.

Table III. Stage-specific survival analysis of breast cancer patients by Her-2/neu amplification status.

\begin{tabular}{|c|c|c|c|c|}
\hline & \multirow[b]{2}{*}{ Cases } & \multirow[b]{2}{*}{ Deaths } & \multicolumn{2}{|c|}{ Overall survival } \\
\hline & & & $\operatorname{HR}(95 \% \mathrm{CI})^{\mathrm{a}}$ & $\operatorname{HR}(95 \% \mathrm{CI})^{\mathrm{b}}$ \\
\hline \multicolumn{5}{|l|}{ Stages 0 and I } \\
\hline Not amplified & 51 & 5 & 1.0 reference & 1.0 reference \\
\hline Amplified & 19 & 2 & $1.1(0.2-5.5)$ & $1.1(0.2-5.4)$ \\
\hline \multicolumn{5}{|l|}{ Stage II } \\
\hline Not amplified & 137 & 28 & 1.0 reference & 1.0 reference \\
\hline Amplified & 65 & 21 & $1.7(1.0-3.1)$ & $1.8(1.0-3.2)$ \\
\hline \multicolumn{5}{|l|}{ Stages III and IV } \\
\hline Not amplified & 16 & 8 & 1.0 reference & 1.0 reference \\
\hline Amplified & 8 & 5 & $1.8(0.6-5.7)$ & $1.9(0.6-6.0)$ \\
\hline \multicolumn{5}{|c|}{ Stages II, III and IV } \\
\hline Not amplified & 153 & 36 & 1.0 reference & 1.0 reference \\
\hline Amplified & 73 & 26 & $1.7(1.0-2.8)$ & $1.7(1.0-2.9)$ \\
\hline
\end{tabular}

${ }^{\mathrm{a} U n a d j u s t e d}$ and ${ }^{\mathrm{b}}$ adjusted for age.

therapy and tamoxifen treatment were comparable between the whole population and the study subset. Age at diagnosis was found to differ, with fewer patients $>45$ being analyzed for Her-2/neu. However, this difference was not statistically significant. The prevalence of Her-2/neu amplification was $26.8 \%$ in tumors assayed by CISH and $41.7 \%$ in those assessed by FISH. No differences in associations with clinicopathological characteristics between these subgroups were found (data not shown). Of the total 313 patients for whom Her-2/neu was evaluated, 100 (31.9\%) were found to have gene amplification. In this study population, Her-2/neu was not found to be significantly associated with any patient or tumor characteristics.

Table II shows the 5-year survival rates as determined by Kaplan-Meier survival functions and the hazards of death associated with Her-2/neu amplification as determined by
Cox proportional hazards regression model for breast cancer cases analyzed by FISH $(\mathrm{N}=108)$, CISH $(\mathrm{N}=205)$ or either technique $(\mathrm{N}=313)$. Her-2/neu amplification was found to be associated with an elevated risk of death, and this relationship persisted after adjustment for patient age, disease stage, menopausal status, chemotherapy, radiotherapy or tamoxifen treatment. The results were similar irrespective of the method employed to detect Her-2/neu amplification. Generally, women with Her-2/neu amplification were $\sim 60 \%$ more likely to die of the disease than patients whose tumors did not have Her-2 neu amplification (HR: 1.6, 95\% CI: 1.0-2.6). This was also evident from the percentage of patients alive 5 years after their cancer diagnosis: $78.1 \%$ of those with amplification, compared to $86.6 \%$ of those without.

To further characterize the negative prognostic effect of Her-2/neu amplification, stage-specific survival analysis was 

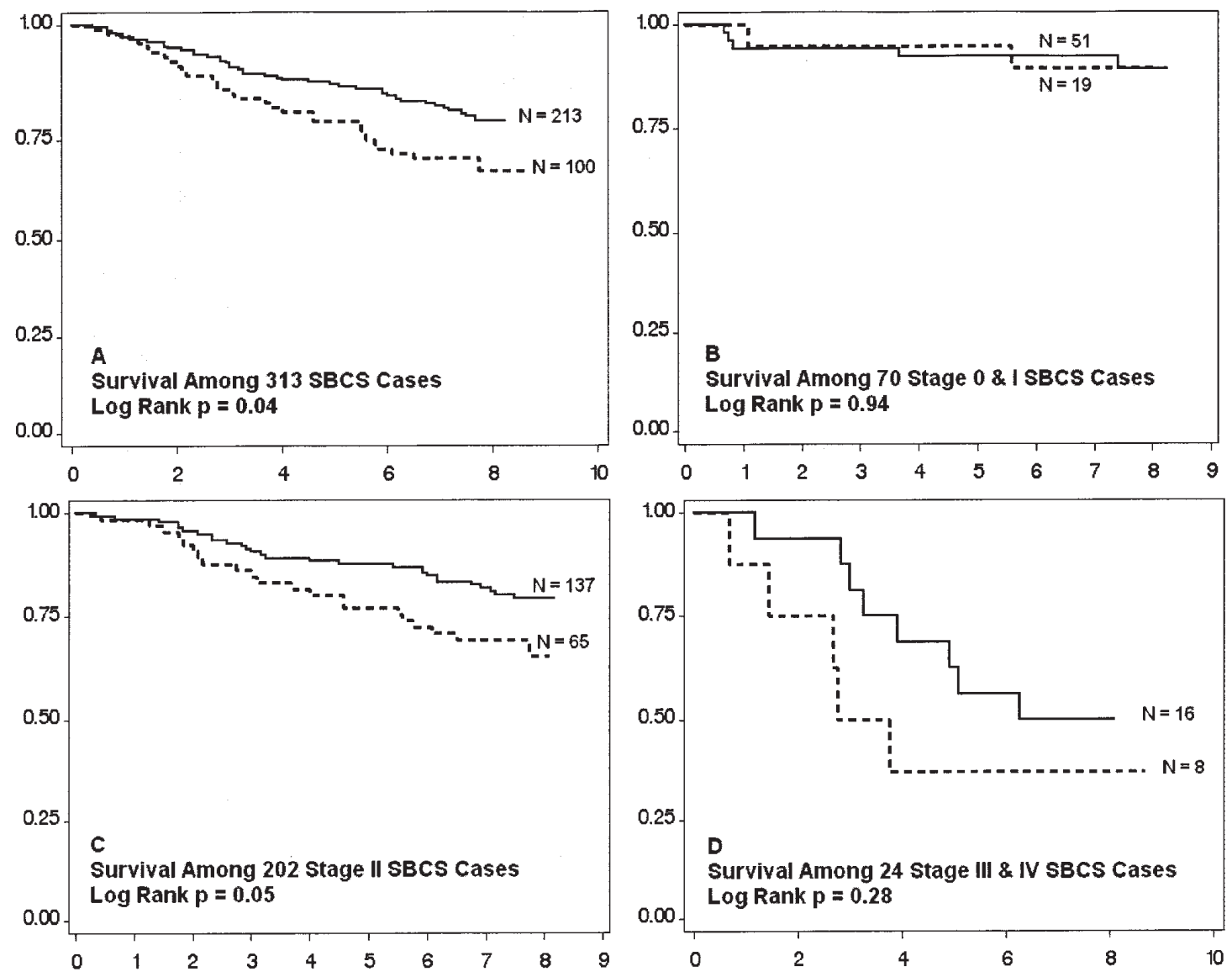

\section{- Her-2/neu Not Amplified - - - Her-2/neu Amplified}

Figure 1. Kaplan-Meier survival functions of breast cancer patients by Her-2/neu amplification status and clinical stage of disease. The survival distribution function is the $\mathrm{y}$-axis and the $\mathrm{x}$-axis is years of survival. The solid line represents patients without while the dotted line represents those with Her-2/neu amplification

conducted. As listed in Table III, Her-2/neu amplification among early stage breast cancer patients was not found to be associated with survival. However, Her-2/neu prognostic effects were evident among later stage patients. Among stage II patients, Her-2/neu was significantly associated with survival and women with amplification were $\sim 80 \%$ more likely to die than those without Her-2/neu amplification (HR: 1.8, 95\% CI: 1.0-3.2). Among stage III and IV patients, the hazard associated with Her-2/neu amplification was large (HR: 1.9, 95\% CI: 0.6-6.0), although the sample size of this strata $(\mathrm{N}=24)$ precluded the estimate from reaching significance. When stage II, III and IV breast cancer cases were combined, a marginally significant hazard of death was found for Her-2/neu and amplification was associated with an $\sim 70 \%$ increase in the risk of death (HR: $1.7,95 \%$ CI: 1.0-2.9). Stage-stratified analysis included adjustment for patient age only, as the limited sample size within strata precluded adjustment for additional variables.

Kaplan-Meier survival functions were found to be in agreement with the results from Cox proportional hazards regression models. Overall survival was significantly worse for patients with Her-2/neu amplification $(\mathrm{p}=0.04)$ as assessed by either FISH or CISH (Fig. 1A). Among patients with in situ or stage I disease, Her-2/neu amplification did not seem to adversely affect prognosis (Fig. 1B), and these results were unchanged when only stage I patients were included (data not shown). However, among stage II patients (Fig. 1C), those with Her-2/neu amplification fared worse $(\mathrm{p}=0.05)$. This difference was also seen in late stage patients (stage III and IV), but again, not to a significant extent (Fig. 1D).

\section{Discussion}

Three hundred and thirteen Chinese women with breast cancer were evaluated for their Her-2/neu status and followed up for a mean of 6.67 years (standard deviation, 1.96). Almost $32 \%(\mathrm{~N}=100)$ were found to have Her-2/neu amplification by either FISH or CISH and this was significantly associated with poorer breast cancer survival. Patients with Her-2/neu amplification were $\sim 60 \%$ more likely to die (HR: 1.6, 95\% CI: 1.0-2.6) than those without, even after adjusting for the effects of age, stage, menopausal status, chemotherapy, radiotherapy and tamoxifen treatment. The relationship between Her-2/neu and breast cancer survival did not depend upon which assay was used to detect amplification. Taken together, the results of this study support a negative prognostic 
role for Her-2/neu in breast cancer survival among Chinese women. To the best of our knowledge, this is the first study to evaluate the relationship between Her-2/neu amplification and breast cancer survival in a large Asian population. Previously, Suo et al reported that Her-2/neu expression was weakly associated with poor prognosis among 107 Chinese breast cancer cases regardless of nodal status, although estimates of the effect were not presented (55). Similarly, Chang et al assessed Her-2/neu with CISH in 104 Korean patients and reported that those with amplification had a worse prognosis, although only median survival times were available (56). In the current study, not only was a significant survival disadvantage found for Chinese breast cancer patients with Her-2/neu amplification, but a stage-specific variation in the hazard of death was also suggested. Among early stage patients (94.3\% stage I), Her-2/neu was not associated with survival, whereas, among stage II patients, amplification was associated with an $\sim 80 \%$ increase in the risk of death (HR: 1.8, 95\% CI: 1.0-3.2). Her-2/neu amplification conferred almost a doubling of the hazard of death among stage III and IV patients (HR: 1.9, 95\% CI: 0.6-6.0), although the estimate was not significant. These stage-specific associations are perhaps not surprising as $>91 \%$ of stage 0 and I patients survive for $>5$ years, while $<84 \%$ of stage II and $52 \%$ of stage III and IV patients survive 5-years after their breast cancer diagnosis.

While differences were seen when our results were stratified with the stage of disease, the hazard of death associated with Her-2/neu amplification did not vary with the type of assay used. Current clinical guidelines to determine Her-2/neu amplification status of breast tumors call for the use of immunohistochemistry (IHC) to determine those that are definitely negative $\left(0\right.$ or $\left.1^{+}\right)$or strongly positive $\left(3^{+}\right)$, followed by FISH to evaluate amplification in the remaining cases $(35,46)$. CISH has been proposed as an alternative method in assessing Her-2/neu for IHC weakly positive tumors $(39,45,47,57)$. CISH alleviates the need for a fluorescence microscope and camera, creates results with permanent signal intensity and allows underlying histomorphology to be simultaneously assessed while being less expensive and faster to conduct $(41,45-47,57)$. One possible limitation to CISH is that while FISH uses two signals, one for Her-2/neu, the other for the centromeric region of chromosome 17, the CISH Her-2/neu copy number does not consider the ploidy of chromosome 17 . However, results between CISH and FISH have been highly consistent when directly compared $(47,48,50,52,57-60)$. The results of two large studies of 157 breast tumors and 193 breast cancer cases found that results from CISH and FISH were 93.6\% concordant ( $\kappa$-coefficient, 0.81$)$ and $93.8 \%$ concordant $(\kappa-$ coefficient, 0.88$)$, respectively $(47,58)$. Several small studies $(\mathrm{N}<100)$ have reported $\kappa$ statistics between 0.85 and 0.91 and concordance rates between 96 and $100 \%(50,57,59)$. Additionally, two larger studies have used tissue microarrays (TMA) to compare FISH and CISH methodologies and one found nearly perfect concordance (99\%) among 110 samples (52) while the other had $94.1 \%$ concordance for 188 breast carcinomas (60). Together, these reports indicate that Her$2 /$ neu amplification evaluated by FISH and CISH is highly comparable, and the assays generally have concordance rates of $93 \%$ or greater. As results from the two assays were in agreement regarding their relationships with clinicopathological characteristics, as well as the association between Her-2/neu and breast cancer survival, we combined FISH and $\mathrm{CISH}$ data in the current study to generate a larger sample size and yield more precise estimates of association.

In addition to being a negative prognostic factor, Her-2/neu amplification has also become an indicator for selecting patients likely to respond to trastuzumab treatment. Patients included in our study were diagnosed and prospectively followed prior to the implementation of trastuzumab. Thus, the association between Her-2/neu amplification and breast cancer survival would not have been affected by this newly introduced targeted therapy. Additionally, the stagedependent effects seen in our study suggest that among early stage patients, there may not be a survival benefit conferred by trastuzumab treatment as Her-2/neu amplification was not a significant prognosticator for these patients. The costs and risks associated with anti-Her-2/neu therapy may be avoided for these early stage patients, although further research on this hypothesis is needed before clinical recommendations can be made. In summary, Her-2/neu amplification, as assessed with either FISH or CISH, was shown to be related to an unfavorable prognosis among Chinese breast cancer patients.

\section{Acknowledgements}

We thank Dr Fan Jin for her contributions in implementing the study in Shanghai and Ms. Qing Wang for her technical assistance in the laboratory. This study would not have been possible without the support of all of the study participants and research staff of the Shanghai breast cancer study. This work was supported by USPHS grants R01CA64277 and R01CA90899 from the National Cancer Institute.

\section{References}

1. Schechter AL, Stern DF, Vaidyanathan L, Decker SJ, Drebin JA, Greene MI and Weinberg RA: The neu oncogene: an erb-Brelated gene encoding a $185,000-\mathrm{Mr}$ tumour antigen. Nature 312: 513-516, 1984 .

2. Akiyama T, Sudo C, Ogawara H, Toyoshima K and Yamamoto T: The product of the human c-erbB-2 gene: a 185-kilodalton glycoprotein with tyrosine kinase activity. Science 232: 1644-1646, 1986 .

3. Muleris M, Almeida A, Malfoy B and Dutrillaux B: Assignment of v-erb-b2 avian erythroblastic leukemia viral oncogene homolog 2 (ERBB2) to human chromosome band 17q21.1 by in situ hybridization. Cytogenet Cell Genet 76: 34-35, 1997.

4. Klapper LN, Glathe S, Vaisman N, Hynes NE, Andrews GC, Sela $M$ and Yarden Y: The ErbB-2/HER2 oncoprotein of human carcinomas may function solely as a shared co-receptor for multiple stroma-derived growth factors. Proc Natl Acad Sci USA 96: 4995-5000, 1999.

5. Yarden Y: Biology of HER2 and its importance in breast cancer. Oncology 61: S1-S13, 2001.

6. Citri A, Skaria KB and Yarden Y: The deaf and the dumb: the biology of ErbB-2 and ErbB-3. Exp Cell Res 284: 54-65, 2003.

7. Marmor MD, Skaria KB and Yarden Y: Signal transduction and oncogenesis by ErbB/HER receptors. Int J Radiat Oncol Biol Phys 58: 903-913, 2004.

8. Lee KF, Simon H, Chen H, Bates B, Hung MC and Hauser C: Requirement for neuregulin receptor erbB2 in neural and cardiac development. Nature 378: 394-398, 1995.

9. Morris JK, Lin W, Hauser C, Marchuk Y, Getman D and Lee KF: Rescue of the cardiac defect in ErbB2 mutant mice reveals essential roles of ErbB2 in peripheral nervous system development. Neuron 23: 273-283, 1999. 
10. Chan R, Hardy WR, Laing MA, Hardy SE and Muller WJ: The catalytic activity of the ErbB-2 receptor tyrosine kinase is essential for embryonic development. Mol Cell Biol 22: 1073-1078, 2002

11. Di Fiore PP, Pierce JH, Kraus MH, Segatto O, King CR and Aaronson SA: erbB-2 is a potent oncogene when overexpressed in NIH/3T3 cells. Science 237: 178-182, 1987.

12. Di Fiore PP, Pierce JH, Fleming TP, Hazan R, Ullrich A, King CR, Schlessinger J and Aaronson SA: Overexpression of the human EGF receptor confers an EGF-dependent transformed phenotype to NIH 3T3 cells. Cell 51: 1063-1070, 1987.

13. Hudziak RM, Schlessinger J and Ullrich A: Increased expression of the putative growth factor receptor p185HER 2 causes transformation and tumorigenesis of NIH 3T3 cells. Proc Natl Acad Sci USA 84: 7159-7163, 1987.

14. Lonardo F, Di ME, King CR, Pierce JH, Segatto O, Aaronson SA and Di Fiore PP: The normal erbB-2 product is an atypical receptor-like tyrosine kinase with constitutive activity in the absence of ligand. New Biol 2: 992-1003, 1990.

15. Karunagaran D, Tzahar E, Beerli RR, Chen X, Graus-Porta D, Ratzkin BJ, Seger R, Hynes NE and Yarden Y: ErbB-2 is a common auxiliary subunit of NDF and EGF receptors: implications for breast cancer. EMBO J 15: 254-264, 1996.

16. Slamon DJ, Clark GM, Wong SG, Levin WJ, Ullrich A and McGuire WL: Human breast cancer: correlation of relapse and survival with amplification of the HER-2/neu oncogene. Science 235: 177-182, 1987.

17. Kallioniemi OP, Holli K, Visakorpi T, Koivula T, Helin HH and Isola JJ: Association of c-erbB-2 protein over-expression with high rate of cell proliferation, increased risk of visceral metastasis and poor long-term survival in breast cancer. Int J Cancer 49: 650-655, 1991.

18. Lovekin C, Ellis IO, Locker A, Robertson JF, Bell J, Nicholson R, Gullick WJ, Elston CW and Blamey RW: c-erbB-2 oncoprotein expression in primary and advanced breast cancer. $\mathrm{Br} \mathrm{J}$ Cancer 63: 439-443, 1991

19. McCann AH, Dervan PA, O'Regan M, Codd MB, Gullick WJ Tobin BM and Carney DN: Prognostic significance of c-erbB-2 and estrogen receptor status in human breast cancer. Cancer Res 51: 3296-3303, 1991.

20. O'Reilly SM, Barnes DM, Camplejohn RS, Bartkova J, Gregory WM and Richards MA: The relationship between cerbB-2 expression, S-phase fraction and prognosis in breast cancer. Br J Cancer 63: 444-446, 1991

21. Gusterson BA, Gelber RD, Goldhirsch A, Price KN, Save-Soderborgh J, Anbazhagan R, Styles J, Rudenstam CM, Golouh R and Reed R: Prognostic importance of c-erbB-2 expression in breast cancer. International (Ludwig) Breast Cancer Study Group. J Clin Oncol 10: 1049-1056, 1992 .

22. Revillion F, Bonneterre J and Peyrat JP: ERBB2 oncogene in human breast cancer and its clinical significance. Eur J Cancer 34: 791-808, 1998

23. Tetu B and Brisson J: Prognostic significance of HER-2/neu oncoprotein expression in node-positive breast cancer. The influence of the pattern of immunostaining and adjuvant therapy. Cancer 73: 2359-2365, 1994.

24. Quenel N, Wafflart J, Bonichon F, de Mascarel I, Trojani M, Durand M, Avril A and Coindre JM: The prognostic value of cerbB2 in primary breast carcinomas: a study on 942 cases. Breast Cancer Res Treat 35: 283-291, 1995.

25. Press MF, Pike MC, Chazin VR, Hung G, Udove JA, Markowicz M, Danyluk J, Godolphin W, Sliwkowski M and Akita R: Her-2/neu expression in node-negative breast cancer: direct tissue quantitation by computerized image analysis and association of overexpression with increased risk of recurrent disease. Cancer Res 53: 4960-4970, 1993.

26. Marks JR, Humphrey PA, Wu K, Berry D, Bandarenko N, Kerns BJ and Iglehart JD: Overexpression of p53 and HER-2/neu proteins as prognostic markers in early stage breast cancer. Ann Surg 219: 332-341, 1994.

27. MacGrogan G, Mauriac L, Durand M, Bonichon F, Trojani M, de Mascarel I and Coindre JM: Primary chemotherapy in breast invasive carcinoma: predictive value of the immunohistochemical detection of hormonal receptors, p53, c-erbB-2, MiB1, pS2 and GST pi. Br J Cancer 74: 1458-1465, 1996.

28. Press MF, Bernstein L, Thomas PA, Meisner LF, Zhou JY, Ma Y, Hung G, Robinson RA, Harris C, El-Naggar A, Slamon DJ, Phillips RN, et al: HER-2/neu gene amplification characterized by fluorescence in situ hybridization: poor prognosis in nodenegative breast carcinomas. J Clin Oncol 15: 2894-2904, 1997.
29. Harbeck N, Ross JS, Yurdseven S, Dettmar P, Polcher M, Kuhn W, Ulm K, Graeff $\mathrm{H}$ and Schmitt M: HER-2/neu gene amplification by fluorescence in situ hybridization allows riskgroup assessment in node-negative breast cancer. Int $\mathrm{J}$ Oncol 14: 663-671, 1999.

30. Carr JA, Havstad S, Zarbo RJ, Divine G, Mackowiak P and Velanovich V: The association of HER-2/neu amplification with breast cancer recurrence. Arch Surg 135: 1469-1474, 2000

31. Riou G, Mathieu MC, Barrois M, Le Bihan ML, Ahomadegbe JC, Benard J and Le MG: c-erbB-2 (HER-2/neu) gene amplification is a better indicator of poor prognosis than protein overexpression in operable breast-cancer patients. Int $\mathrm{J}$ Cancer 95: 266-270, 2001

32. Schmidt M, Lewark B, Kohlschmidt N, Glawatz C, Steiner E, Tanner B, Pilch H, Weikel W, Kolbl H and Lehr HA: Long-term prognostic significance of HER-2/neu in untreated nodenegative breast cancer depends on the method of testing. Breast Cancer Res 7: R256-R266, 2005.

33. Baselga J, Tripathy D, Mendelsohn J, Baughman S, Benz CC, Dantis L, Sklarin NT, Seidman AD, Hudis CA, Moore J, Rosen PP, Twaddell T, et al: Phase II study of weekly intravenous trastuzumab (Herceptin) in patients with HER 2/neu-overexpressing metastatic breast cancer. Semin Oncol 26: 78-83, 1999.

34. Cobleigh MA, Vogel CL, Tripathy D, Robert NJ, Scholl S, Fehrenbacher L, Wolter JM, Paton V, Shak S, Lieberman G and Slamon DJ: Multinational study of the efficacy and safety of humanized anti-HER2 monoclonal antibody in women who have HER2-overexpressing metastatic breast cancer that has progressed after chemotherapy for metastatic disease. J Clin Oncol 17: 2639-2648, 1999.

35. Carlson RW, Moench SJ, Hammond ME, Perez EA, Burstein HJ, Allred DC, Vogel CL, Goldstein LJ, Somlo G, Gradishar WJ, Hudis CA, Jahanzeb M, et al: HER2 testing in breast cancer: NCCN Task Force report and recommendations. J Natl Compr Cancer Netw 4: S1-S22, 2006.

36. Jacobs TW, Gown AM, Yaziji H, Barnes MJ and Schnitt SJ: Comparison of fluorescence in situ hybridization and immunohistochemistry for the evaluation of HER-2/neu in breast cancer. J Clin Oncol 17: 1974-1982, 1999.

37. Pauletti G, Dandekar S, Rong H, Ramos L, Peng H, Seshadri R and Slamon DJ: Assessment of methods for tissue-based detection of the HER-2/neu alteration in human breast cancer: a direct comparison of fluorescence in situ hybridization and immunohistochemistry. J Clin Oncol 18: 3651-3664, 2000.

38. Tubbs RR, Pettay JD, Roche PC, Stoler MH, Jenkins RB and Grogan TM: Discrepancies in clinical laboratory testing of eligibility for trastuzumab therapy: apparent immunohistochemical false-positives do not get the message. J Clin Oncol 19: 2714-2721, 2001.

39. Barrett C, Magee H, O'Toole D, Daly S and Jeffers M: Amplification of the HER-2 gene in breast cancers testing 2+ weak positive by HercepTest ${ }^{\mathrm{TM}}$ immunohistochemistry: false positive or false negative IHC? J Clin Pathol 60: 690-693, 2007.

40. Sidoni A, Ferri I, Cavaliere A, Bellezza G, Scheibel M and Bucciarelli E: Detection of HER-2/neu (c-erbB-2) overexpression and amplification in breast carcinomas with ambiguous immunohistochemical results. A further contribution to defining the role of fluorescent in situ hybridization. Anticancer Res 26: $2333-2337,2006$

41. Jacobs TW, Gown AM, Yaziji H, Barnes MJ, Schnitt SJ: Specificity of HercepTest in determining HER-2/neu status of breast cancers using the United States food and drug administration-approved scoring system. J Clin Oncol 17: 1983-1987, 1999.

42. Kakar S, Puangsuvan N, Stevens JM, Serenas R, Mangan G, Sahai $\mathrm{S}$ and Mihalov ML: HER-2/neu assessment in breast cancer by immunohistochemistry and fluorescence in situ hybridization: comparison of results and correlation with survival. Mol Diagn 5: 199-207, 2000.

43. O'Grady A, Flahavan CM, Kay EW, Barrett HL and Leader MB: HER-2 analysis in tissue microarrays of archival human breast cancer: comparison of immunohistochemistry and fluorescence in situ hybridization. Appl Immunohistochem Mol Morphol 11: $177-182,2003$

44. Ross JS and Gray GS: Targeted therapy for cancer: the HER-2/neu and Herceptin story. Clin Leadersh Manag Rev 17 : 333-340, 2003.

45. Madrid MA and Lo RW: Chromogenic in situ hybridization (CISH): a novel alternative in screening archival breast cancer tissue samples for HER-2/neu status. Breast Cancer Res 6: R593-R600, 2004 
46. Yaziji H, Goldstein LC, Barry TS, Werling R, Hwang H, Ellis GK, Gralow JR, Livingston RB and Gown AM: HER-2 testing in breast cancer using parallel tissue-based methods. JAMA 291: 1972-1977, 2004.

47. Tanner M, Gancberg D, Di LA, Larsimont D, Rouas G, Piccart MJ and Isola J: Chromogenic in situ hybridization: a practical alternative for fluorescence in situ hybridization to detect HER-2/neu oncogene amplification in archival breast cancer samples. Am J Pathol 157: 1467-1472, 2000.

48. Dandachi N, Dietze O and Hauser-Kronberger C: Chromogenic in situ hybridization: a novel approach to a practical and sensitive method for the detection of HER2 oncogene in archival human breast carcinoma. Lab Invest 82: 1007-1014, 2002.

49. Gupta D, Middleton LP, Whitaker MJ and Abrams J: Comparison of fluorescence and chromogenic in situ hybridization for detection of HER-2/neu oncogene in breast cancer. Am J Clin Pathol 119: 381-387, 2003.

50. Hauser-Kronberger C and Dandachi N: Comparison of chromogenic in situ hybridization with other methodologies for HER2 status assessment in breast cancer. J Mol Histol 35: 647-653, 2004.

51. Li-Ning TE, Ronchetti R, Torres-Cabala $\mathrm{C}$ and Merino MJ: Role of chromogenic in situ hybridization (CISH) in the evaluation of HER2 status in breast carcinoma: comparison with immunohistochemistry and FISH. Int J Surg Pathol 13: 343-351, 2005.

52. Loring P, Cummins R, O'Grady A and Kay EW: HER 2 positivity in breast carcinoma: a comparison of chromogenic in situ hybridization with fluorescence in situ hybridization in tissue microarrays, with targeted evaluation of intratumoral heterogeneity by in situ hybridization. Appl Immunohistochem Mol Morphol 13: 194-200, 2005.

53. Gao YT, Shu XO, Dai Q, Potter JD, Brinton LA, Wen W, Sellers TA, Kushi LH, Ruan Z, Bostick RM, Jin F and Zheng W: Association of menstrual and reproductive factors with breast cancer risk: results from the Shanghai Breast Cancer Study. Int J Cancer 87: 295-300, 2000.
54. Zheng W, Gao YT, Shu XO, Wen W, Cai Q, Dai Q and Smith JR Population-based case-control study of CYP11A gene polymorphism and breast cancer risk. Cancer Epidemiol Biomarkers Prev 13: 709-714, 2004

55. Suo Z, Yang H, Mei Q, Skovlund E, Cui J and Nesland JM: Type 1 protein tyrosine kinases in Chinese breast carcinomas: a clinicopathologic study. Int J Surg Pathol 9: 177-187, 2001.

56. Chang E, Lee A, Lee E, Lee H, Shin O, Oh S and Kang C: HER-2/neu oncogene amplification by chromogenic in situ hybridization in 130 breast cancers using tissue microarray and clinical follow-up studies. J Korean Med Sci 19: 390-396, 2004.

57. Arnould L, Denoux Y, MacGrogan G, Penault-Llorca F, Fiche M, Treilleux I, Mathieu MC, Vincent-Salomon A, Vilain MO and Couturier J: Agreement between chromogenic in situ hybridisation (CISH) and FISH in the determination of HER 2 status in breast cancer. Br J Cancer 88: 1587-1591, 2003.

58. Isola J, Tanner M, Forsyth A, Cooke TG, Watters AD and Bartlett JM: Interlaboratory comparison of HER-2 oncogene amplification as detected by chromogenic and fluorescence in situ hybridization. Clin Cancer Res 10: 4793-4798, 2004.

59. Gong Y, Gilcrease M and Sneige N: Reliability of chromogenic in situ hybridization for detecting HER-2 gene status in breast cancer: comparison with fluorescence in situ hybridization and assessment of interobserver reproducibility. Mod Pathol 18: 1015-1021, 2005.

60. Park K, Kwak K, Kim J, Lim S and Han S: c-myc amplification is associated with HER2 amplification and closely linked with cell proliferation in tissue microarray of non-selected breast cancers. Hum Pathol 36: 634-639, 2005. 